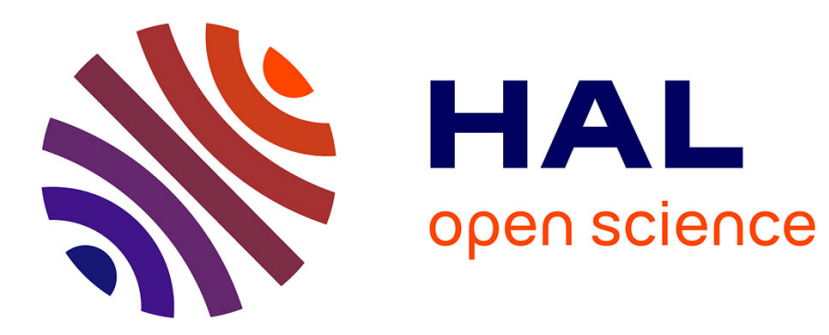

\title{
Using Column Generation To Solve A Coal Blending Problem
}

\author{
Daniel de Wolf, Stéphane Auray, Yves Smeers
}

\section{To cite this version:}

Daniel de Wolf, Stéphane Auray, Yves Smeers. Using Column Generation To Solve A Coal Blending Problem. RAIRO - Operations Research, 2015, 49 (1), pp.15-37. 10.1051/ro/2014033 . halshs02396784

\section{HAL Id: halshs-02396784 \\ https://shs.hal.science/halshs-02396784}

Submitted on 6 Dec 2019

HAL is a multi-disciplinary open access archive for the deposit and dissemination of scientific research documents, whether they are published or not. The documents may come from teaching and research institutions in France or abroad, or from public or private research centers.
L'archive ouverte pluridisciplinaire HAL, est destinée au dépôt et à la diffusion de documents scientifiques de niveau recherche, publiés ou non, émanant des établissements d'enseignement et de recherche français ou étrangers, des laboratoires publics ou privés. 


\title{
USING COLUMN GENERATION TO SOLVE A COAL BLENDING PROBLEM
}

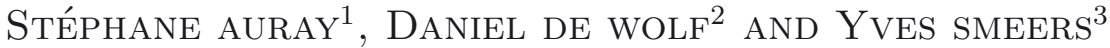

\begin{abstract}
In this paper, we formulate and solve a real life coal blending problem using a Column Generation Approach. The objective of the model is to prescribe optimal mixes of coal to produce coke. The problem is formulated as a mixed integer program. It involves various types of constraints arising from technical considerations of the blending process. The model also incorporates nonlinear constraints. It results in a large-scale problem that cannot be solved by classical operations research methods. Defining three heuristic methods based on column generation techniques, this paper proposes reasonable solutions for the industry.
\end{abstract}

Keywords. Column generation, coal blending.

Mathematics Subject Classification. 90B30, 49M27.

\section{INTRODUCTION}

In this paper, we consider a real life problem: a coal blending problem for coke production. The model includes not only quality constraints for the coke but also all the constraints resulting from the different transportation modes and the inventory constraints.

Different types of constraints should be considered during the production. Firstly, the coke is subject to a collection of quality constraints which, in some

Received August 26, 2013. Accepted May 21, 2014.

1 CREST-Ensai, Rue Blaise Pascal, 35172 Bruz, France; Equippe, Université du Côte d'Opale and CIRPEE. stephane.auray@ensai.fr

2 TVES, Université du Littoral Côte d'Opale 189B avenue Maurice Schumann, BP 5526, 59379 Dunkerque Cedex 1, France daniel.dewolf@univ-littoral.fr

3 Center for Operations Research and Econometrics, UCL, 34 voie du Roman Pays, 1348 Louvain-La-Neuve, Belgium. yves.smeers@uclouvain.be 
cases, may depend on the clients. These constraints are all linear. But there are also, for technical reasons, a maximum number of coal types in the mix. This number is dependant on the number of gates of the plant. A mix consists simply of using particular ratios of different coal types during a certain period of time.

There is also, for technical reasons, a minimal proportion for each coal present in the mix. As we shall see in Section 3, taking these conditions into account requires the introduction of integer variables and nonlinear constraints. This may be linearized under a restrictive condition (see Williams [10]).

The coke delivered to the customers can be obtained using different mixes of coals. However, the total number of mixes used by a plant in a given time period has an upper bound: there is a significant fixed cost involved in changing the mix and only two different mixes can be used each month. Finally, we must take into account capacity constraints as well as minimum production levels.

The industrial problem tackled in this paper is more difficult than the classical coal blending problem of the Operations Research literature considered by Sarker and Gunn [6] or Greenberg [4] due to the presence of binary variables. These binary variables are required to model the minimum and/or maximum level of use of each coal. Sarker and Gunn [6] solve the tactical planning/coal blending problem. This leads to a nonlinear nonconvex problem for which solutions are computed using simple Successive Linear Programming. They used the Lasdon SLP implementation based on the XLP code of Marsten (see Lasdon [5]). Greenberg [4] looks at the same pooling problem that arises when blending materials, but considers a different application, namely the blending of crude or refined petroleum. He presents a new method based upon computational geometry which provides exact answers to questions of sensitivity analysis for this nonlinear nonconvex problem.

We solve a more complicated problem through the following column generation technique (see Vanderbeck and Wolsey [7] for an exact algorithm for IP column generation, Vanderbeck [8] for the branch-and-price algorithm or Desaulniers, Desrosiers and Solomon [2] for a didactic introduction to the use of column generation technique in integer programming). For each time period, and each plant, by fixing the coal delivery prices at the entry of the plant, i.e. a price that represents the unit purchasing and transportation costs, we determine the optimal coal mix for one unit of production. This results in subproblems. Then, the Master problem determines the level of use of these mixes. The Master problem also determines the coal delivery plan to the plants and the coke delivery plan to the clients. As we shall see in Section 4, the solution of the Master problem leads to reviewing the delivery prices at the entry of the plant for each coal. New mixes based on these new prices are generated by solving the subproblems. Consequently, new columns are generated for the Master problem. Note that there are also integer variables at the upper level, since only a limited number of different mixes can be considered at each time period.

We would like to mention that other types of constraints have been considered in coal blending problems for coke production. For instance, Vasko et al. [9] consider coke oven wall pressure or coke stability constraints. They propose candidate coals 
TABle 1. Choice of indices.

\begin{tabular}{cl}
\hline$c$ & coals \\
\hline$b$ & coals coming by boat \\
$r$ & coals coming by railways \\
$k$ & plants \\
$t$ & time periods \\
$m$ & mixes \\
$h$ & harbours \\
$a$ & clients \\
\hline
\end{tabular}

to produce coke by solving first a mixed integer linear programming model (MILP) similar to the subproblems that we consider (coal quantity for one ton of mixes) and then they use a binary decision tree that ensure the production of high-quality coke. Sample results are presented on hypothetical, but realistic, data. In our model, however, the set of coals used by the company does not pose significant coke oven wall pressure or coke stability problems. So we do not take into consideration this complicating constraints.

The main contribution of this paper is to solve a real world problem encountered within this industry, which is a large-scale problem intractable by classical operations research methods. Defining three heuristics methods based on column generation techniques, we furnished reasonable solutions to the industrial company.

\section{Problem DESCRIPTION}

The manager of a coke production company wants to determine the operations schedule for the next three months for the five coke production units situated in Belgium. We use $t$ as the index for the time periods. The three time periods correspond to the months of January to March. We denote days $s_{t}$ the number of days for month $t$.

These five plants, denoted by $k$, produce different types of coke by mixing different types of coals. The mixes are indexed by $m$. Different type of clients, indexed by $a$, are served by the company. This results in different quality constraints on the mix.

The demand is assumed to be known with accuracy for the first three months of the year. The different coals, indexed by $c$, are purchased from several countries and brought to Belgium by means of two transportation modes, namely boat or rail. The buying prices of the different coals and the transportation costs from producer to the plant are also given. Table 1 summarizes the indices used in the model.

\subsection{Plants Description}

Each production plant $k$ is characterized by a daily capacity of plant - cap $k$ - which is the maximum amount of coal that can be handled by the plant (see 
TABLE 2. Plant characteristics.

\begin{tabular}{cccccc}
\hline$k$ & cap $_{k}$ & minuse $_{k}$ & gates $_{k}$ & mincoal $_{k}$ & maxcoal $_{k}$ \\
\hline 1 & 2300 & $60 \%$ & 8 & $5 \%$ & $100 \%$ \\
2 & 2850 & $60 \%$ & 4 & $15 \%$ & $35 \%$ \\
3 & 1250 & $75 \%$ & 8 & $10 \%$ & $100 \%$ \\
4 & 3500 & $60 \%$ & 8 & $10 \%$ & $100 \%$ \\
5 & 3500 & $60 \%$ & 8 & $10 \%$ & $100 \%$ \\
\hline
\end{tabular}

TABLE 3. Production cost (euro per ton of coal).

\begin{tabular}{lccc}
\hline prodcost $_{k t}$ & $t=1$ & $t=2$ & $t=3$ \\
\hline$k=1$ & 11.450 & 11.400 & 11.350 \\
$k=2$ & 18.175 & 18.100 & 18.025 \\
$k=3$ & 38.150 & 38.000 & 37.850 \\
$k=4$ & 24.125 & 24.025 & 23.925 \\
$k=5$ & 11.300 & 11.250 & 11.200 \\
\hline
\end{tabular}

Tab. 2). Since the plant can never been stopped, there is also a minimal utilization rate for each plant, denoted minuse $_{k}$ for plant $k$. To put the coals into the oven, there is only a limited number of entry gates, denoted gates $k$ for plant $k$. This implies that the number of coal types in the mix is limited. There are also a minimal and a maximal proportion for each coal in the mix, denoted respectively mincoal $_{k}$ and maxcoal $_{k}$ for plant $k$. Note that these two parameters are function of the plant and are independent of the coal type: in fact, the minimal and maximal proportion depend on the charging machinery of the plants. Since the plants were constructed at different periods, the technology used is different, which explains the differences from plant to plant.

Plants also differ by their unitary production cost. We denote by prodcost $_{k t}$ the unitary production cost of plant $k$ at time period $t$ (see Tab. 3).

\subsection{COAL CHARACTERISTICS}

The firm can use 16 types of coal during this production horizon. These types differ by their characteristics such as the ash rate, denoted $a s h_{c}$ for coal $c$, the sulfur rate, denoted sul $_{c}$, the alkali rate, denoted $a_{l} k_{c}$, the volatile part, denoted $v_{c o l}$ and the wet part, denoted wet. The wet part is the unusable part of the coal. One also distinguishes three classes among the coals: the "High Volume", denoted HV, the "Mid Volume", denoted MV, and the "Low Volume", denoted LV (see Tab. 4). 
TABLE 4. Coal characteristics.

\begin{tabular}{ccccccc}
\hline$c$ & ash & sulf $_{c}$ & alk $_{c}$ & vol $_{c}$ & wet $_{c}$ & Type \\
\hline 1 & $4.99 \%$ & $.85 \%$ & $.12 \%$ & $17.89 \%$ & $6.63 \%$ & LV \\
2 & $5.53 \%$ & $.70 \%$ & $.09 \%$ & $17.48 \%$ & $7.77 \%$ & LV \\
3 & $7.72 \%$ & $.94 \%$ & $.31 \%$ & $22.71 \%$ & $10.15 \%$ & LV \\
4 & $8.30 \%$ & $.67 \%$ & $.14 \%$ & $21.00 \%$ & $8.00 \%$ & LV \\
5 & $8.07 \%$ & $.70 \%$ & $.16 \%$ & $23.60 \%$ & $9.47 \%$ & MV \\
6 & $4.83 \%$ & $.88 \%$ & $.16 \%$ & $30.19 \%$ & $6.80 \%$ & HV \\
7 & $6.86 \%$ & $1.15 \%$ & $.24 \%$ & $29.90 \%$ & $7.54 \%$ & HV \\
8 & $6.14 \%$ & $.84 \%$ & $.22 \%$ & $31.39 \%$ & $8.66 \%$ & HV \\
9 & $6.01 \%$ & $.82 \%$ & $.19 \%$ & $32.75 \%$ & $6.29 \%$ & HV \\
10 & $6.45 \%$ & $.88 \%$ & $.17 \%$ & $33.08 \%$ & $7.20 \%$ & HV \\
11 & $7.44 \%$ & $.66 \%$ & $.24 \%$ & $27.43 \%$ & $6.45 \%$ & HV \\
12 & $7.70 \%$ & $.71 \%$ & $.23 \%$ & $32.09 \%$ & $6.81 \%$ & HV \\
13 & $7.00 \%$ & $.98 \%$ & $.32 \%$ & $25.10 \%$ & $8.00 \%$ & MV \\
14 & $7.60 \%$ & $.57 \%$ & $.18 \%$ & $19.30 \%$ & $10.14 \%$ & LV \\
15 & $5.79 \%$ & $.82 \%$ & $.18 \%$ & $24.39 \%$ & $8.99 \%$ & MV \\
16 & $5.30 \%$ & $.72 \%$ & $.13 \%$ & $33.50 \%$ & $7.90 \%$ & HV \\
\hline
\end{tabular}

\subsection{Avallability, Delivery and Departure prices of the CoAls}

Some of the coals are coming by boat. We index by $b$ these coals (see Fig. 1). They mainly come from North America and from Australia. There are two possible arrival harbours that we index by $h$. There is an initial coal inventory at the

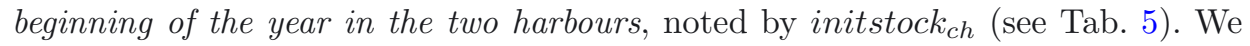
denote $\operatorname{expq}_{c t}$ deliveries corresponding to already ordered quantities expected for some of these coals. The landing harbour is not yet decided.

The other coals are delivered by rail. We index by $r$ these coals. They mainly come from Germany and from Eastern Europe. There is no storage capacity for these coals. Deliveries, noted $e x p q_{c t}$, are also expected for these coals. The final destination of these quantities is not yet decided (see Tab. 5).

The USD is the reference currency for the coals coming by boat. The euro is used for the other coals. Expected exchange rates for the next three months are given in Table 5. Prices are given at the harbour or station of departure in Table 5 where the relevant currency is also given for each coal. By multiplying the price in foreign currency by the expected exchange rate, we obtain the price of coal $c$ at time period $t$ in $€$ denoted price $_{c t}$. 


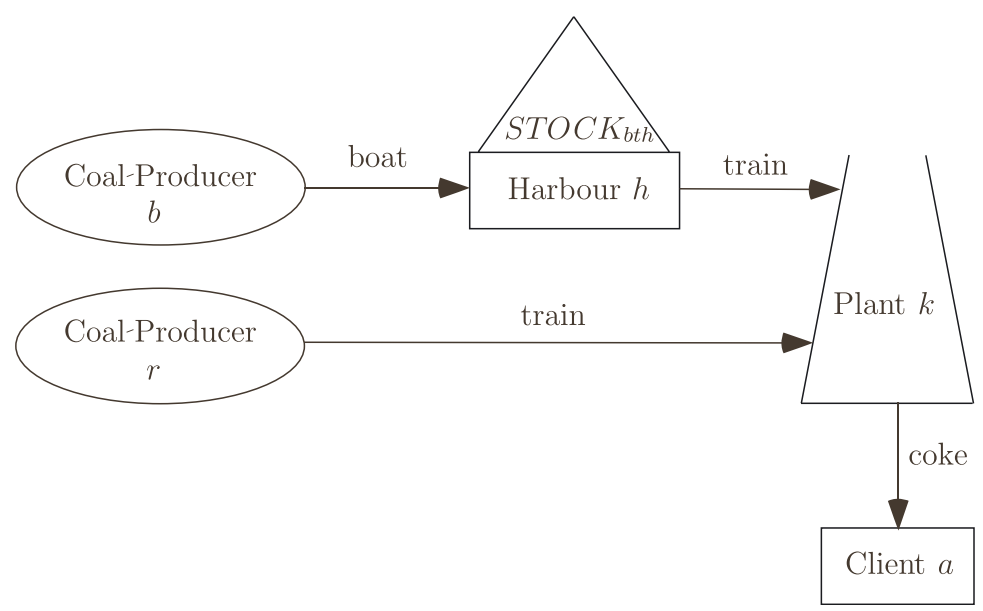

FiguRE 1. Supply chain for the input to the plants.

TABLE 5. Initial inventory, expected quantities and coal prices.

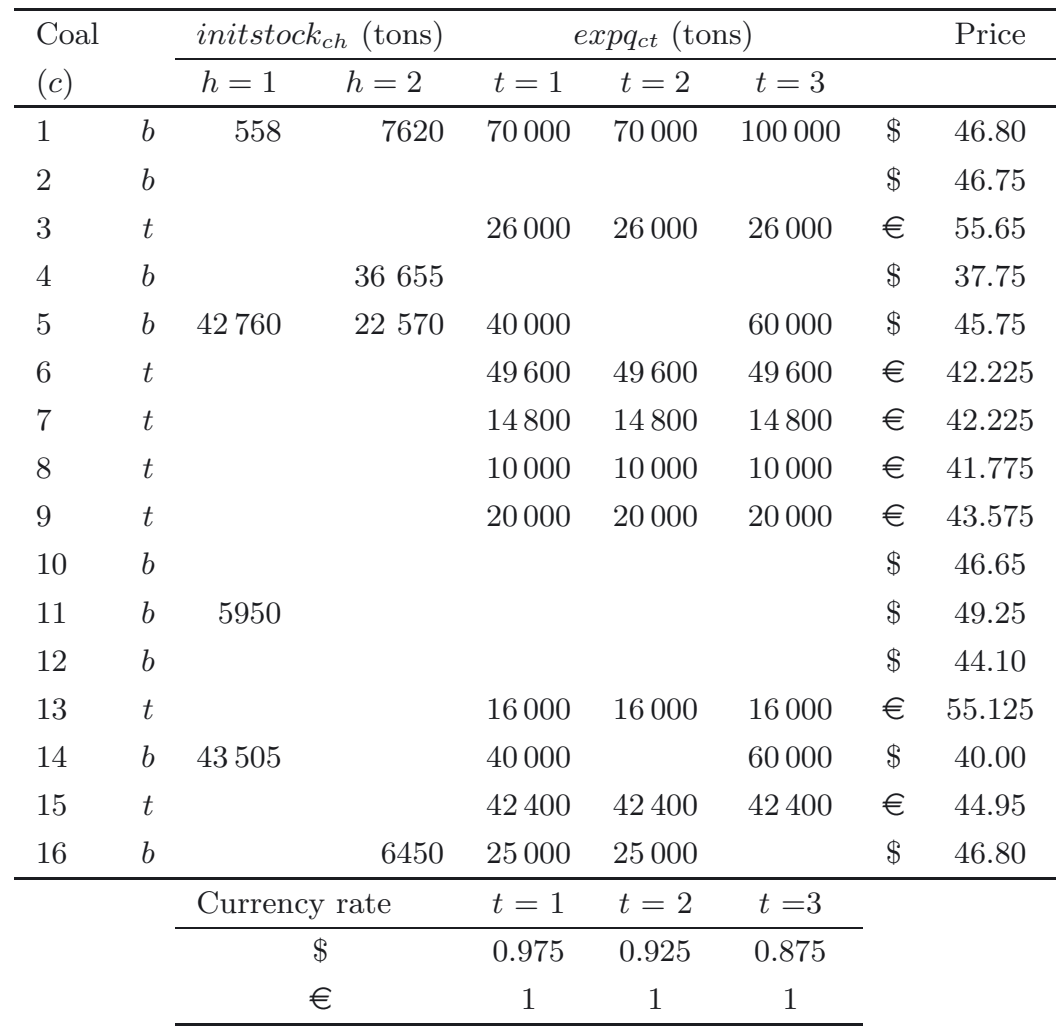


TABLE 6. Boat or rail transportation costs.

\begin{tabular}{cccccccccc}
\hline (\$/ton) & \multicolumn{10}{c}{ boatcost $_{c h}$} \\
\cline { 2 - 10 } & $c=1$ & $c=2$ & $c=4$ & $c=5$ & $c=10$ & $c=11$ & $c=12$ & $c=14$ & $c=16$ \\
\hline$h=1$ & 5.1 & 4.5 & 10.25 & 8.15 & 3.75 & 3.30 & 0 & 7.5 & 5.10 \\
$h=2$ & 5.1 & 4.5 & 10.25 & 8.15 & 3.75 & 3.30 & 0 & 7.5 & 5.10 \\
\hline$(€ /$ ton $)$ & transpcost $_{h k}$ & \multicolumn{7}{c}{ railcost $_{c k}(€ /$ ton $)$} \\
\cline { 2 - 10 } & $h=1$ & $h=2$ & $c=3$ & $c=6$ & $c=7$ & $c=8$ & $c=9$ & $c=13$ & $c=15$ \\
\hline$k=1$ & 4.4675 & 4.4675 & 9.155 & 4.67 & 4.67 & 4.67 & 9.155 & 9.155 & 4.67 \\
$k=2$ & 2.6375 & 3.25 & 7.39 & 4.2625 & 4.2625 & 4.2625 & 7.39 & 7.39 & 4.2625 \\
$k=3$ & $+\infty$ & 0 & - & - & - & - & - & - & - \\
$k=4$ & 3.86 & 3.86 & 8.29 & 6.08 & 6.08 & 6.08 & 8.29 & 8.29 & 6.08 \\
$k=5$ & 2.460 & 4.105 & 7.7475 & 2.31 & 2.31 & 2.31 & 7.7475 & 7.7475 & 2.31 \\
\hline
\end{tabular}

\subsection{The TRANSPORTATION COSTS}

The transportation costs by boat to the harbour, denoted boatcost ${ }_{c h}$, are given in $\$$ per ton of coal (see Tab. 6). As can be seen, there is no difference for the transportation costs between the two arrival harbours. Handling costs at the harbour, denoted dockcost d $_{h}$ are the same at the two harbours due to the competition between the harbours: $3.3875 €$ per ton. Transportation costs from harbours to plants, denoted transpcost $_{h k}$ are given in $€$ per ton (see Tab. 6).

Note that there is no transportation cost between harbour 2 and plant 3, the plant being located in the harbour area. Consequently, plant 3 is only supplied from harbour 2. The four other plants are also supplied by rail. The transportation costs by rail between the departure station and the plants, denoted railcost ${ }_{c k}$, are given in $€$ per ton by Table 6 for all coals coming directly from the production site to the plant by rail.

\subsection{Characteristics of the Demand}

The coke company must satisfy the demand of 13 clients for the next three months. We use $a$ as index for the client. The demand of client $a$ in time period $t$ is denoted dem $_{a t}$ (see Tab. 7). In order to minimize the coke transportation cost, the plant requested by each client is given. A few of them (clients 4 and 6) can be supplied by two plants, the distances to the two plants being similar.

We explain now the quality constraints that the coal mix must meet. The first one concerns the volatile rate. The volatile rate of the mix must be between $24 \%$ and 26\%. We denote these two parameters as minvol and maxvol. The second constraint concerns the ash rate. The mix has a maximal ash rate depending on the client. We denote maxash $_{a}$ this quantity for client $a$. The third specification concerns the sulfur rate. There is a lower and upper limit on sulfur, denoted minsulf $f_{a}$ and $\operatorname{maxsulf} f_{a}$, which also depends on the client. The fourth specification concerns

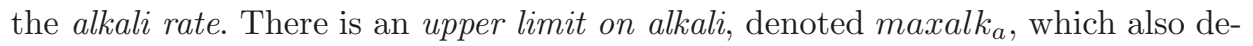
pends on the client $a$. The fifth specification concerns the Low Volume rate. The 
TABLE 7. Demand for the next three months.

\begin{tabular}{lcccc}
\hline demat & $t=1$ & $t=2$ & $t=3$ & Plant \\
\hline Client 1 & 11500 & 12600 & 12600 & 3 \\
Client 2 & & 4000 & 4000 & 1 \\
Client 3 & 45000 & 45000 & 45000 & 1 \\
Client 4 & 7000 & 8000 & 8000 & 2 or 3 \\
Client 5 & 2000 & 2000 & 2000 & 3 \\
Client 6 & 16500 & 24800 & 14400 & 1 or 2 \\
Client 7 & 26700 & 19400 & 14800 & 2 \\
Client 8 & & 3500 & & 2 \\
Client 9 & 6000 & 6000 & 5000 & 1 \\
Client 10 & 16000 & 16000 & 14000 & 2 \\
Client 11 & 12000 & 12000 & 12000 & 3 \\
Client 12 & 58452 & 49002 & 51644 & 4 \\
Client 13 & 68516 & 68132 & 71162 & 5 \\
\hline
\end{tabular}

lower and upper limits on Low Volume, denoted minlv $v_{a}$ and maxlv $v_{a}$, also depend on the client (see Tab. 8). For these three characteristics (ash, sulfur and alkali), there is a multiplicative coefficient from the mix to the coke: they are denoted respectively multash, multsulf and multalk (see Tab. 8).

For all minimal and/or maximal characteristic rates that depend on the client, we shall consider as specification for the mix of the plant the specification of the most restrictive client that the plant has to serve.

The sixth specification concerns the rate in "Mid Volume". Here there are lower and upper bounds on Mid Volume, denoted minmv (0.25) and maxmv (0.25) respectively, which do not depend on the client. In fact, for technical reasons, there is a fixed rate of $1 / 4$ of Mid volume coals. The seventh specification concerns the soft rate. There is an upper bound on Soft coal, denoted maxsoft (0.10), which does not depend on the client. The only soft coal is coal 12 . The eighth specification concerns the Australian coal rate. Here, for commercial reasons, there is an upper bound, denoted maxaus (0.30), which does not depend on the client. The only Australian coal is coal 4.

Finally, note that the number of mixes that can be used for each plant per period, is limited. This maximum number of mixes, denoted maxmix $_{k t}$, is equal to 2 mixes per month for each plant. The different mixes will be indiced by $m$.

\section{Problem Formulation}

We have already introduced the following indices (see Tab. 1): the coals are indexed by $c$, the plants by $k$, the time periods by $t$, the mixes by $m$, the harbours 
TABLE 8. Specifications which depend on the client.

\begin{tabular}{|c|c|c|c|c|c|c|}
\hline Client & $\operatorname{maxash}_{a}$ & $\operatorname{minsulf} f_{a}$ & $\operatorname{maxsulf} f_{a}$ & $\operatorname{maxalk}_{a}$ & minlva & $\max l v_{a}$ \\
\hline Client 1 & 10. & & 1. & .30 & 30. & 100. \\
\hline Client 2 & 10. & & 1. & .30 & 30. & 100. \\
\hline Client 3 & 10. & & 1. & .30 & 30. & 100. \\
\hline Client 4 & 10. & & 1. & .30 & 30. & 100. \\
\hline Client 5 & 10. & & 1. & .30 & 30. & 100. \\
\hline Client 6 & 9.5 & .7 & .9 & .30 & 30. & 100. \\
\hline Client 7 & 9.5 & .7 & .9 & .30 & 30. & 100. \\
\hline Client 8 & 10. & & 1. & .30 & 40. & 50. \\
\hline Client 9 & 10. & & 1. & .30 & 30. & 100. \\
\hline Client 10 & 10. & & 1. & .30 & 30. & 100. \\
\hline Client 11 & 10. & & 1. & .30 & 30. & 100. \\
\hline Client 12 & 9.5 & .7 & .9 & .30 & 30. & 100. \\
\hline Client 13 & 9.5 & .7 & .9 & .30 & 30. & 100. \\
\hline \multirow{2}{*}{\multicolumn{3}{|c|}{$\begin{array}{l}\text { Multiplicative coefficient } \\
\text { from the mix to the coke }\end{array}$}} & Ash & \multicolumn{2}{|c|}{ Sulfur } & Alkali \\
\hline & & & 1.32 & \multicolumn{2}{|c|}{0.92} & 1.32 \\
\hline
\end{tabular}

by $h$ and the clients by $a$. To facilitate the notation, we have also introduced the subindices $b$ for the coals coming by boat and $r$ for the coals coming by rail.

\subsection{Choice of DECision VARIABles}

The first set of variables concerns the production of coke in the different plants: we denote by $C O A L_{\text {cktm }}$ the quantity of coal $c$ used in plant $k$ at the time period $t$ in the mix $m$. We introduce only for convenience the variable $S U M_{k t m}$, which is the total quantity of coals for plant $k$ in the mix $m$ at the time period $t$. These two quantities are given in tons. To account for the limited number of coal in the mix, we introduce the binary variables $C O A L P R E S_{c k t m}$ to indicate that coal $c$ is present in the mix $m$ for plant $k$ at time period $t$. To account for the limited number of mixes at each time period, we introduce the binary variables MIXPRE $S_{k t m}$ to indicate that mix $m$ is used for plant $k$ at time period $t$. Table 9 summarizes this choice of variables.

A second set of variables is used to manage the deliveries and inventories of coals (see Fig. 2).

We denote by $O R D Q_{c t}$ the new ordered quantity of coal $c$ at time period $t$ and assume that the orders placed in period $t$ are also delivered in period $t$. Consequently, this quantity adds to the expected quantities at time period $t$, exp $q_{c t}$ which are given (see Sect. 2). We denote by $X B O A T_{b t h}$ the quantity of coal $b$ coming by boat that is sent to harbour $h$ at time period $t$ and by $X R A I L_{r k t}$ the 
TABLE 9. Variables for the coke production.

\begin{tabular}{lc}
\hline Variable & Definition \\
\hline$C O A L_{c k t m}$ & quantity of coal $c$ used in the mix $m$ at period $t$ in mix $m$, \\
$S U M_{k t m}$ & total coal quantity for mix $m$ at plan $k$ for period $t$, \\
$C O A L P R E S_{c k t m}$ & indicator that coal $c$ is in the mix $m$ (binary), \\
$M I X P R E S_{k t m}$ & indicator the the mix $m$ is used for plant $k$ (binary). \\
\hline
\end{tabular}

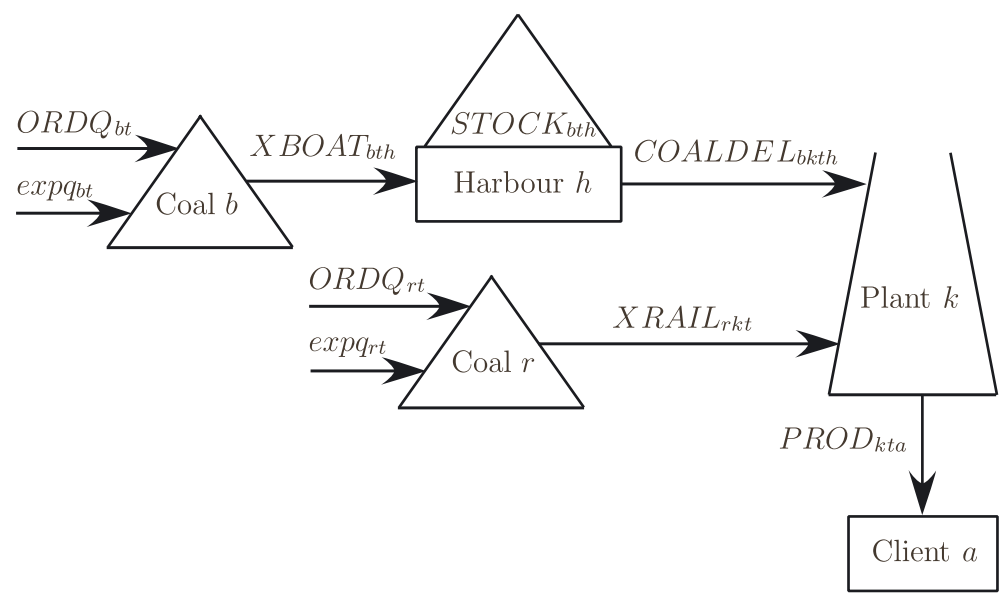

Figure 2. Decision variables for the coal deliveries and inventories.

quantity of coal $r$ coming by rail that is sent to coke plant $k$ at time period $t$. We let $S T O C K_{b t h}$ be the inventory of coal delivered by boat $b$ at the end of time period $t$ in harbour $h$ and $C O A L D E L_{b k t h}$ be the coal $b$ deliveries from harbour $h$ to plant $k$ at time period $t$. Last we denote by $P R O D_{k t a}$ the tons of coke produced in plant $k$ at time period $t$ for client $a$. These variables are necessary to compute the coke transportation plan, since some clients can be supplied by more than one plant. Table 10 summarizes this choice of variables.

\subsection{Mathematical expression of the objective}

The objective function is the sum of six following terms:

$$
\begin{aligned}
\min z= & \sum_{c} \sum_{t} \text { price }_{c t}\left(\text { expq }_{c t}+O R D Q_{c t}\right) \\
& +\sum_{b} \sum_{t} \sum_{h}\left(\text { boatcost }_{b h}+\text { dockcost }_{h}\right) X B O A T_{b t h}
\end{aligned}
$$


TABLE 10. Variables for the coal deliveries and inventories.

\begin{tabular}{ll}
\hline Variable & Definition \\
\hline ORDQ & new ordered quantity of coal $c$ at period $t$, \\
XBOATbth & $\begin{array}{l}\text { quantity of coal } b \text { sent to harbour } h \\
\text { at the period } t,\end{array}$ \\
STOCK $K_{b t h}$ & inventory of coal $b$ in the harbour $h$ at the end of period $t$, \\
$C O A L D E L_{b k t h}$ & coal deliveries from harbour $h$ to plant $k$ \\
$X R A I L_{r k t}$ & quantity of coal $r$ delivered at time $t$ to plant $k$. \\
$P R O D_{k t a}$ & coke produce at plant $k$ for client $a$ at time $t$. \\
\hline
\end{tabular}

$$
\begin{aligned}
& +\sum_{b} \sum_{t} \sum_{h} \text { rate } \cdot \text { delprice }_{b t h} \text { STOCK }_{b t h} \\
& +\sum_{b} \sum_{k} \sum_{t} \sum_{h} \text { transpcost }_{h k} C O A L D E L_{b k t h} \\
& +\sum_{r} \sum_{k} \sum_{t} \text { railcost }_{r k} X R A I L_{r k t} \\
& +\sum_{k} \sum_{t} \sum_{m} \text { prodcost }_{k t} S U M_{k t m}
\end{aligned}
$$

- the coal purchasing cost (1) where price $_{c t}$ is the coal price $c$ at period $t$,

- the boat transportation cost and the handling cost at the harbours (2) where boatcost $_{b h}$ is the boat transportation cost and dockcost $_{h}$ is the handling cost at harbour,

- the holding inventory cost for each quantity of coal stored at the arrival harbour (3) where rate is the monthly opportunity rate $(0,5 \%)$ and delprice $_{b t h}$ is the delivery price, i.e the sum of the purchasing cost, the boat transportation cost and the handling cost at the harbour:

$$
\text { delprice }_{b t h}=\text { price }_{b t}+\text { boatcost }_{b h}+\text { dockcost }_{h}
$$

- the transportation cost from harbour to plants (4) where transpcost $_{h k}$ is the unitary transportation cost from the harbour to the plant,

- the transportation cost by rail (5) with railcost rk $_{\text { }}$ the unitary rail cost,

- the production costs (6) with prodcost $_{k t}$ the unitary production cost. 
3.3. Mathematical expression of the CONStRaints

We have the following relations between theses variables:

$$
\begin{aligned}
& S U M_{k t m}=\sum_{c} C O A L_{c k t m} \\
& C O A L_{c k t m} \leq C O A L P R E S_{c k t m} \text { cap }_{k} \text { days }_{t} \\
& S U M_{k t m} \leq M I X P R E S_{k t m} \text { cap }_{k} d a y s_{t} \\
& \text { minuse }_{k} \text { cap }_{k} \text { days }_{t} \leq \sum_{m} S U M_{k t m} \leq \text { cap }_{k} \text { days }_{t} \\
& e x p q_{b t}+O R D Q_{b t}=\sum_{h} X B O A T_{b t h} \\
& e x p q_{r t}+O R D Q_{r t}=\sum_{k} X R A I L_{r k t} \\
& \sum_{h} C O A L D E L_{b k t h}=\sum_{m} C O A L_{b k t m} \\
& X R A I L_{r k t}=\sum_{m} C O A L_{r k t m} \\
& \sum_{m} M I X P R E S_{k t m} \leq \text { maxmix }_{k t} \\
& S T O C K_{b t h}-S T O C K_{b, t-1, h}=X B O A T_{b t h}-\sum_{k} C O A L D E L_{b k t h} \\
& \sum_{m} \sum_{c}\left(1-\text { wet }_{c}\right) * C O A L_{c k t m}=\sum_{a} P R O D_{k t a} \\
& \sum P R O D_{k t a} \geq d e m_{a t} \\
& k \text { delivering } a \\
& \sum_{c} C O A L P R E S_{c k t m} \leq \text { gates }_{k} \\
& \operatorname{mincoal}_{k} C O A L P R E S_{c k t m} \leq \frac{C O A L_{c k t m}}{S U M_{k t m}} \\
& \frac{C O A L_{c k t m}}{S U M_{k t m}} \leq \operatorname{maxcoal}_{k} C O A L P R E S_{c k t m}
\end{aligned}
$$

- Equation (7) computes the sum of coals for each mix and each time period. 
- Equations (8) and (9) are the definition of the binary variables: namely they indicate the presence of the coal or the use of the mix. Note that $\operatorname{cap}_{k}$ is the daily coal entry capacity for plant $k$ and days $s_{t}$ is the number of days in time period $t$. This number of days is needed since capacity is a daily capacity and the variables are monthly quantities of coal entering the plant.

- Equation (10) concerns the minimal utilization rate and capacities of plants.

- Equation (11) indicates that the total amount of coal delivered by boat must be allocated between the two harbours since equation (12) indicates that the total amount of coal delivered by rail must be allocated between the plants.

- Equation (13) is the balance for each coal coming by boat at each plant since equation (14) is the balance for each coal delivered by rail.

- Equation (15) concerns the maximal number of mixes for each plant and each time period.

- Equation (16) gives the balance at the end of time period $t$ for coal $b$ at each harbour $h$ since equation (17) gives the balance at the exit of the plants.

- Equation (18) is the demand satisfaction.

- Equation (19) deals with the maximal number of coal types in the mix.

- Equation (20) defines the minimal use of each coal in a mix since equation (21) concerns the maximal use of each coal in a mix.

We have two types of variables:

- the continuous variables which must be nonnegative:

$$
\begin{aligned}
& C O A L_{c k t m}, S U M_{k t m}, C O A L D E L_{b k t h}, P R O D_{k t a}, \\
& X B O A T_{b t h}, X R A I L_{r k t}, O R D Q_{b t}, S T O C K_{b t h} \geq 0
\end{aligned}
$$

- and the binary variables:

$$
\text { COALPRES } S_{c k t m}, M I X P R E S_{k t m} \in\{0,1\}
$$

Note also that the two last constraints (20) and (21) are nonlinear. All the other quality constraints on the mix are easy to write. They are listed in Appendix A.

\section{Solution Method}

Except for constraints (20) and (21), all the constraints of the problem are purely linear. Note that the left hand side of constraint (20) must be multiplied by the variable COALPRES, otherwise all the coals would be present in the mix. 
The solution technique followed by Sarker and Gunn [6] is to define for each ratio $C O A L_{c k t m} / S U M_{k t m}$ a variable, say $f_{c k t m}$, introducing for each $c, k, t$ and $m$ the constraint:

$$
f_{c k t m} S U M_{k t m}=C O A L_{c k t m} .
$$

They obtain a problem with a nonlinear part of bilinear type (product of variables). Heuristics for solving such problems have been proposed in the Operations Research literature. They are related to techniques for solving fractional linear programs and they resort to successive linear programming (SLP).

However, in our problem, integer variables remain, since constraints (20) and (21) are written as:

$$
\text { mincoal }_{k} C O A L P R E S_{c k t m} \leq f_{c k t m} \leq \operatorname{maxcoal}_{k} C O A L P R E S_{c k t m}
$$

This paper proposes three heuristic methods, based on column generation ideas. The problem formulated in Section 3 has two types of binary variables: one called $C O A L P R E S_{\text {cktm }}$ to indicate the presence of coal $c$ in the mix $m$ for plant $k$ at time period $t$. The other one, called MIXPRES $S_{k t m}$ indicates that the mix $m$ is used for plant $k$ at time period $t$. We know that column generation procedures solve only LP problems. In our heuristic method, we keep the binary variable in the subproblem (for limiting the number of coal types in the mix) and in the main program (for limiting the number of mixes used for each plant and each time period).

The subproblems are defined as follows. For each plant, and for each time period, initially we consider the delivery price at the entry of the plant as the sum of the coal price and the total transportation cost to the plant. We look for a mix of one ton that satisfies all the quality constraints on the mix. This gives an initial column of coal proportions for each plant for each time period. Note that imposing the sum of coals to be equal to one is a simple manner to linearize the two nonlinear constraints (20) and (21).

In the master problem, we shall determine the level of utilization of these mixes in order to meet the demand of the several clients at minimal production, transportation and coal purchasing costs. By multiplying the level of use of a mix by the column of the coal proportions in the mix for a particular plant, we obtain the coal quantities needed for the plant at the time period.

To update the delivery price at the entry of the plant, we consider the dual price of the balance at the entry of the plant constraints (13) or (14) depending on the transportation mode. In fact, these dual variables give the marginal effect on the objective function of an unitary increase of the delivery of this coal to the plant.

For each subproblem, the initial coal delivery price at the entry of the plant is computed as the sum of the departure price and transportation costs. One main iteration is the solution of the 15 subproblems ( 5 plants $\times 3$ time periods) and of one main problem. At the end of the first main iteration, we update the initial delivery price at the entry of the plant by replacing the delivery price by the dual price of constraints (13) or (14). 


\subsection{The SUB PROGRAMS}

The sub problems $\mathrm{SP}(\mathrm{k}, \mathrm{t})$ where $p(c, k, t)$ is the delivery price of the coal $c$ to plant $k$ at time period $t$ are defined as follows:

$$
\begin{aligned}
& \min z=\sum_{c} p(c, k, t) C O A L_{c k t} \\
& \begin{cases}\sum_{c} C O A L_{c k t} & =1 \\
\sum_{c} C O A L P R E S_{c k t} & \leq \text { gates }_{k} \\
\text { mincoal }_{k} C O A L P R E S_{c k t} & \leq C O A L_{c k t} \\
C O A L_{c k t} & \leq \text { maxcoal }_{k} C O A L P R E S_{c k t}\end{cases} \\
& \left\{\begin{array}{l}
\sum_{c} \text { ash }_{c} \text { multash } C O A L_{c k t} \leq \underset{a \text { delivered by } k}{\min } \text { maxash }_{a} S U M_{k t} \\
\sum_{c} \text { sulf }_{c} \text { multsulf } C O A L_{c k t} \geq \max _{a \text { delivered by } k} \text { minsulf }_{a} S U M_{k t}
\end{array}\right.
\end{aligned}
$$

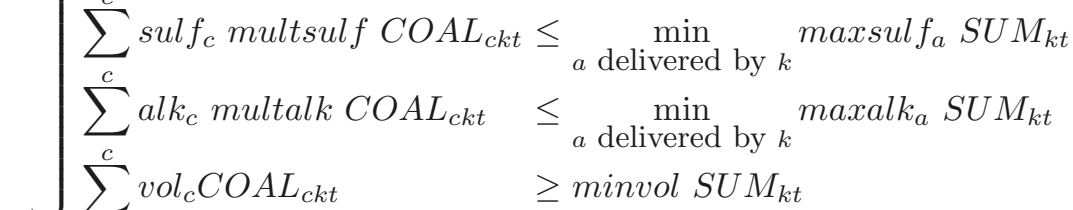

$$
\begin{aligned}
& \text { st } \\
& \begin{array}{l}
\sum_{c}^{c} \operatorname{vol}_{c} C O A L_{c k t} \\
\sum^{c} C O A L_{c k t}
\end{array} \\
& \leq \text { maxvol } S U M_{k t} \\
& \geq \max _{a \text { delivered by } k} \text { minlv }_{a} S U M_{k t} \\
& \leq \min _{a \text { delivered by } k} \operatorname{maxlv}_{a} S U M_{k t} \\
& \leq \operatorname{maxmv} S U M_{k t} \\
& \geq \operatorname{minmv} S U M_{k t} \\
& \leq \text { maxsoft } S U M_{k t} \\
& \sum^{c \text { is Soft }} C O A L_{c k t} \leq \text { maxaus } S U M_{k t}
\end{aligned}
$$

Every variables must be nonnegative behalve COALPRES which is binary.

The subproblems correspond to the following task: find, for each time period and each plant, the optimal mix for one unit of coal mix. The constraints include all the mix quality constraints, the maximal number of coals and the minimal and maximal rate for each coal in the mix. The only variables are variables $C O A L_{c}$ and $C O A L P R E S_{c}$. Recall that the objective coefficients include at the first iteration the coal purchasing cost, transportation cost, handling cost and the production cost. At the following iterations, we only consider the sum of the dual variable and the production cost. 
Consequently, we need to solve as many problems as there are plants and time periods. We note $\operatorname{coal}(c, k, t, m)$ the proportion of coal $c$ used in mix $m$ (initially, $m$ is set to 1$)$ at plant $k$ at time period $t$.

\subsection{The MAIN PROBlem}

The main problem corresponds to the determination of the delivery planning of coals to the plants, the allocation of ordered quantities to the harbours, the determination of the level of use of the mixes generated by the subproblems for each plant and each time period and finally the coke transportation plan to the clients. We obtain the following main problem:

$$
\begin{aligned}
& \min z=\sum_{c} \sum_{t} \text { price }_{c t}\left(\operatorname{expq}_{c t}+O R D Q_{c t}\right)+\sum_{b} \sum_{t} \sum_{h} \text { rate } \cdot \text { delprice }_{b t h} \\
& S T O C K_{b t h}+\sum_{b} \sum_{t} \sum_{h}\left(\text { boatcost }_{b h}+\text { dockcost }_{h}\right) X B O A T_{b t h} \\
& +\sum_{b} \sum_{k} \sum_{t} \sum_{h} \text { transpcost }_{h k} C O A L D E L_{b k t h} \\
& +\sum_{r} \sum_{k} \sum_{t} \text { railcost }_{r k} X R A I L_{r k t}+\sum_{k} \sum_{t} \sum_{m} \text { prodcost }_{k t} S U M_{k t m}
\end{aligned}
$$

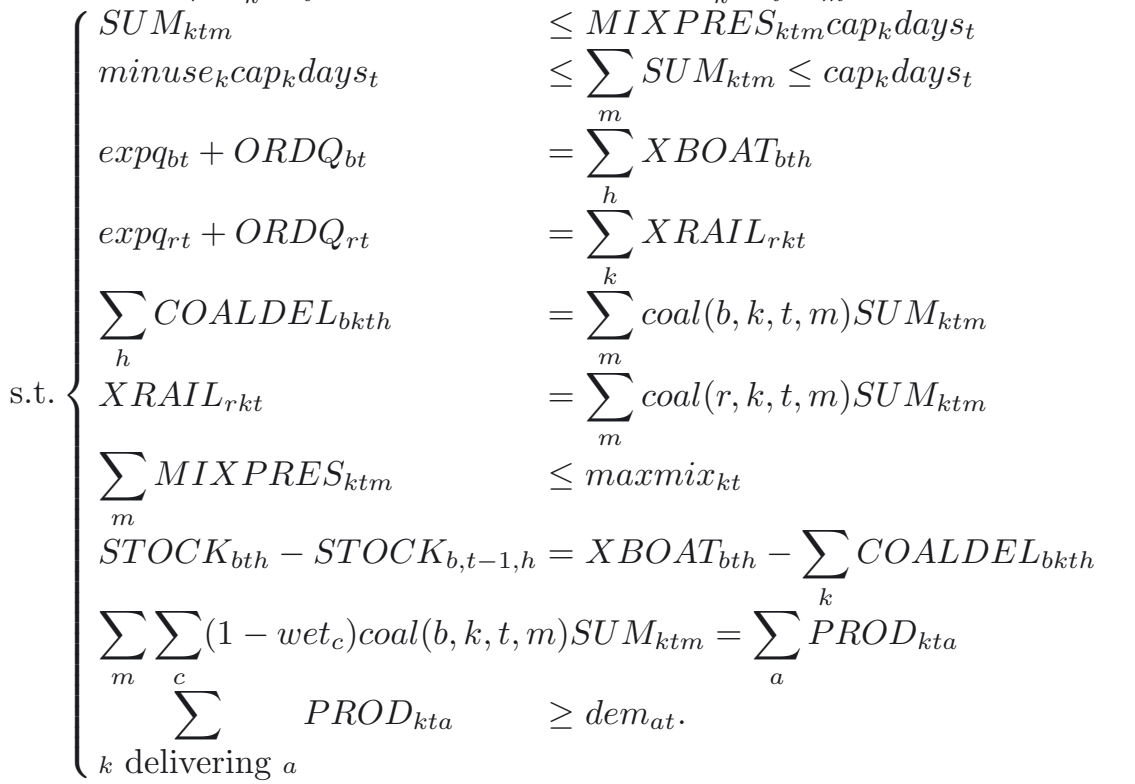

Every variables must be nonnegative behalve MIXPRES which is binary.

This gives a mixed integer program with binary variables MIXPRES since a maximal number of different mixes for each plant at each time period must be imposed. This program can also be solved by GAMS/OSL.

At the first iteration, there are 481 rows and 556 columns. Each iteration adds 15 constraints (15 "rows") and 30 variables ("columns") to the main problem (see Tab. 11). The new variables correspond to the 15 new mixes binary variables 
TABLE 11. Evolution of the MP objective function.

\begin{tabular}{lcccc}
\hline Iteration & $\begin{array}{c}\text { Objective } \\
\text { value }(€)\end{array}$ & $\begin{array}{c}\text { Execution } \\
\text { time }(\mathrm{s})\end{array}$ & $\begin{array}{c}\text { Number } \\
\text { of rows }\end{array}$ & $\begin{array}{c}\text { Number } \\
\text { of columns }\end{array}$ \\
\hline 1 & 91569578.20 & 3 & 481 & 556 \\
2 & 79432349.83 & 4 & 496 & 586 \\
3 & 75029945.98 & 11 & 511 & 616 \\
4 & 71579163.48 & 48 & 526 & 646 \\
5 & 69789373.33 & 49 & 541 & 676 \\
\hline 6 & 68615626.73 & 522 & 556 & 706 \\
7 & 68514039.00 & 52 & 571 & 736 \\
8 & 68513503.25 & 409 & 586 & 766 \\
9 & 68428567.03 & 119 & 601 & 796 \\
10 & 68393561.65 & 4151 & 616 & 826 \\
\hline 11 & 68388314.23 & 664 & 631 & 856 \\
12 & 68361242.08 & 4403 & 646 & 886 \\
13 & 68358137.05 & 494 & 661 & 916 \\
14 & 68349665.80 & 2412 & 676 & 946 \\
15 & 68347547.93 & 1865 & 691 & 976 \\
\hline $16^{*}$ & 68346480.40 & 3184 & 706 & 1006 \\
\hline
\end{tabular}

* Stopping criterion satisfied.

and the to 15 new mixes utilization levels. The new constraints correspond to the computation of the $S U M$ variables corresponding to the 15 new mixes.

\subsection{The GLOBAL PROCESS}

The global process includes 3 levels of inner loops in GAMS/OSL (see Brooke, Kendrick and Meeraus [1]):

- the first loop on the main iterations,

- the second loop on the time periods,

- and the third loop on the plants.

It can be summarized by the following procedure:

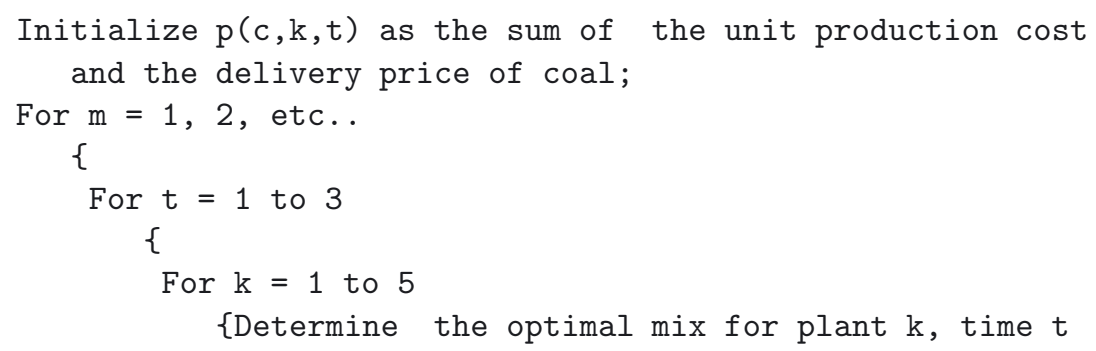




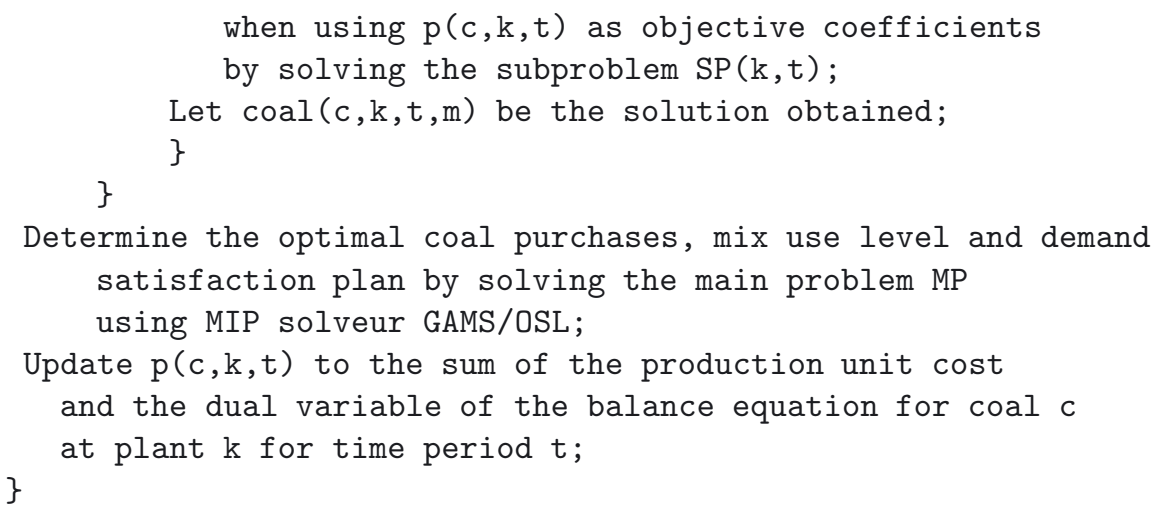

The stopping criterion is as follows: stop if there are no columns pricing out. Before analyzing these results, let us stress the fact that the procedure we propose is heuristic. In fact, with an alternative organization of the master problem and subproblem hierarchy, we can achieve a better objective function value (see Sect. 5).

Let us conclude this section with a few explanations on the "dual prices" used in the column generation. In fact, our master problem is a mixed integer problem due to the MIXPRES binary variables. It is known in mathematical programming that the dual information is only valid for a linear program. We explain how this dual information is generated. We have solved this MIP problem using GAMS/OSL. After the solver has found the optimal solution, GAMS fixes the levels of the integer variables and reruns the model as an LP model to obtain the dual variables values. As an alternative heuristic, one could also use the dual prices of the LP relaxation of the whole MIP problem. We refer to Section 5 for the comparison of the results of the two possible choices for generating the dual information.

\section{NumericAl RESUltS}

Table 11 presents the successive objective function values for the main program, the execution time for GAMS/OSL and the size of the main program.

Two conclusions can be taken from this table. The first one is the important objective function decrease (about $2500000 €$ per iteration) during the first five iterations. This global cost reduction continues at a lower rate during the following iterations. Secondly, the heuristic converges in only 16 main iterations. Recall also that, since we use a heuristic method, the solution can be suboptimal.

Now, let us say a few words about two other heuristics that were suggested to us to solve the problem. The first one is a variant of our column generation method that was suggested to us by Professor Yves Pochet from CORE, Université Catholique de Louvain, Belgium. Since the only difficulty in the main program is the fact that there are binary variables $\left(C O A L P R E S_{c k t m}\right)$ in a product with another variable $S U M_{k t m}$ (see Eq. 21), one can, for the main program, fix the coals present in the mix instead of fixing their proportion in the mix. This implies 
TABLE 12. MP objective function for the second heuristic.

\begin{tabular}{lcccc}
\hline Iteration & $\begin{array}{c}\text { Objective } \\
\text { value }(€)\end{array}$ & $\begin{array}{c}\text { Execution } \\
\text { time }(\mathrm{s})\end{array}$ & $\begin{array}{c}\text { Number } \\
\text { of rows }\end{array}$ & $\begin{array}{c}\text { Number } \\
\text { of columns }\end{array}$ \\
\hline 1 & 89378751.35 & 3 & 1124 & 796 \\
2 & 76709252.58 & 23 & 1782 & 1066 \\
3 & 75052581.23 & 18 & 2440 & 1336 \\
4 & 70284765.43 & 215 & 3098 & 1606 \\
5 & 68484730.45 & 49 & 541 & 676 \\
\hline 6 & 68458216.33 & 1497 & 4414 & 2146 \\
7 & 68408431.40 & 543 & 5072 & 2416 \\
8 & 68374826.85 & 1010 & 5730 & 2686 \\
9 & 68362017.08 & 599 & 6388 & 2956 \\
10 & 68353850.75 & 8165 & 7046 & 3226 \\
\hline 11 & 68348399.20 & 10803 & 8362 & 3766 \\
12 & 68345582.43 & 10803 & 646 & 886 \\
13 & 68342647.50 & 10803 & 9020 & 4036 \\
\hline $14^{*}$ & 68341879.48 & 7575 & 9678 & 4306 \\
\hline
\end{tabular}

* Stopping criterion satisfied.

that variables sent from the lower to the upper level are not the COAL variables, but only the COALPRES variables. This also implies that we must impose, in the main program, all the quality constraints on the mix listed in appendix A.

Table 12 presents the evolution of the objective function value, the execution time for GAMS/OSL and the size of the main program for this second heuristic method.

A slightly better solution (68 $341879.48 €$ instead of $68346480.40 €$ ) was obtained after 14 main iterations but took much longer (14 hours 28 min instead of 5 hours 6 minutes for the first heuristic). This increase in the execution time is due to the fact that the size of the main problem is increased (compare the last two columns of Tables 11 and 12). From this example, one can conclude that the second method is not competitive, as it gives a similar solution in much more time. This example also points out the fact that the proposed solution procedure is heuristic since the second solution method gives a slightly better solution.

Finally, we present a third heuristic that was suggested to us by Professor Etienne Loute from Facultés Universitaires Saint Louis, Brussels, Belgium. The only difference between this and the first method is the choice of the dual information to update the coal delivery prices for the subproblem. Instead of using the dual information given at the optimal solution of the MIP version of the master problem, the relaxed version of this master problem is solved and the dual information of this RMIP problem is then used. Table 13 presents the evolution of the objective 
TABLE 13. MP objective function for the third heuristic.

\begin{tabular}{lccc}
\hline Iteration & $\begin{array}{c}\text { Objective } \\
\text { value }(€)\end{array}$ & $\begin{array}{c}\text { Execution time } \\
\text { RMIP }(\mathrm{s})\end{array}$ & $\begin{array}{c}\text { Execution time } \\
\text { MIP }(\mathrm{s})\end{array}$ \\
\hline 1 & 91569578.20 & 2 & 2 \\
2 & 79432349.83 & 2 & 4 \\
3 & 75029945.98 & 2 & 19 \\
4 & 72105817.88 & 2 & 24 \\
5 & 68835693.58 & 3 & 1071 \\
\hline 6 & 68503629.70 & 2 & 468 \\
7 & 68433685.88 & 3 & 1243 \\
8 & 68400568.13 & 2 & 75 \\
9 & 68379477.03 & 2 & 624 \\
10 & 68358511.35 & 2 & 270 \\
\hline 11 & 68349689.18 & 2 & 390 \\
12 & 68349689.18 & 2 & 385 \\
13 & 68348287.88 & 2 & 2458 \\
\hline $14^{*}$ & 68346804.38 & 2 & 555 \\
\hline
\end{tabular}

* Stopping criterion satisfied.

function value, the execution time for GAMS/OSL for the RMIP and for the MIP version of the master program.

This third solution method is close to the standard column generation technique. At the end of the procedure, the integrality of variables for the main problem is restored as follows: after solving the LP-relaxation, a branch and bound procedure is performed with these columns.

A slightly more expansive solution (68 $346804.38 €$ instead of 68346480.40 $€)$ was obtained after 14 main iterations but in less time (2 h 10 min instead of $5 \mathrm{~h} 6 \mathrm{~min}$ with our method). All these run times were in fact acceptable to the industry since we are determining the planning for three months. The solution procedure was presented to the industrial company and helped the company in both directions. On one side, it helps the industrial company to discover the limiting constraints of its production problem. For example, the industrial company was not aware that the number of entering gates is an important constraint for the problem. In fact, if we allow as many coal type as we want in the mix, the production costs decreases. On the other side, our heuristic has helped the industrial company to decrease its production cost for the three months.

\section{Conclusions}

In this paper, we have formulated and solved a real world problem. It concerns the integration of the distribution and mixing of coals to satisfy the demand of 
coke of a set of customers throughout a planning horizon. The modelling of the problem implies a large number of constraints with binary variables. The binary variables come from the limitation of the number of coals in the mixes at each plant at each time period and from the limitation of the number of mixes used for each plant and each time period. Some of the constraints were nonlinear. To solve this difficult problem, we have presented three heuristics based on the idea of the column generation technique. The implementation of the heuristics has helped the industrial company to reduce its production cost.

In the future, we intend to add new quality constraints on the mix which are nonlinear and that can not be linearized by the present heuristic method. It concerns upper and lower bound on the Gieseler Fluidity, which is a nonlinear function of the coal quantities in the mix (see Appendix B for a complete presentation of these new constraints).

Acknowledgements. The authors would like to thank Professor Yves Pochet of CORE for suggesting to us the other solution technique, professor Etienne Loute for valuable suggestions to improve the presentation of the paper and finally, Gráinne Corry of University of Littoral and Catherine De Wolf of MIT, for carefully reading this paper.

\section{Appendix A. Linear QUALity COnStraints on the MiX}

- maximal ash rate of the mix:

$$
\sum_{c} a_{\text {sh }} \text { multash } C O A L_{c k t m} \leq \min _{a \text { delivered by } k} \text { maxash }_{a} S U M_{k t m}
$$

- minimal sulfur rate of the mix:

$$
\sum_{c} \text { sulf }_{c} \text { multsulf } C O A L_{c k t m} \geq \underset{a \text { delivered by } k}{\max } \text { minsulf }_{a} S U M_{k t m}
$$

- maximal sulfur rate of the mix:

$$
\sum_{c} \text { sulf }_{c} \text { multsulf } C O A L_{c k t m} \leq \underset{a \text { delivered by } k}{\min } \operatorname{maxulf} f_{a} S U M_{k t m}
$$

- maximal alkali rate of the mix:

$$
\sum_{c} \text { alk }_{c} \text { multalk } C O A L_{c k t m} \leq \underset{a \text { delivered by } k}{\min } \operatorname{maxalk}_{a} S U M_{k t m}
$$

- minimal and maximal volatiles rate of the mix:

$$
\text { minvol } S U M_{k t m} \leq \sum_{c} \operatorname{vol}_{c} C O A L_{c k t m} \leq \operatorname{maxvol} S U M_{k t m}
$$

- minimal Low Volume rate of the mix:

$$
\sum_{c \text { is a Low Volume }} C O A L_{c k t m} \geq \max _{a \text { delivered by } k} \operatorname{minlv}_{a} S U M_{k t m}
$$


TABLE 14. Lower and upper bounds for $I 10$ and $I 20$.

\begin{tabular}{lcc}
\hline Parameter & $\begin{array}{c}\text { Lower } \\
\text { limit }\end{array}$ & $\begin{array}{c}\text { Upper } \\
\text { limit }\end{array}$ \\
\hline$I 10$ & & 23. \\
$I 20$ & 76.5 & \\
\hline
\end{tabular}

- maximal Low Volume rate of the mix:

$$
\sum_{c \text { is a Low Volume }} C O A L_{c k t m} \leq \min _{a \text { delivered by } k} \operatorname{maxlv}_{a} S U M_{k t m}
$$

- minimal and maximal Mid Volume rate of the mix:

$$
\text { minmv } S U M_{k t m} \leq \sum_{c \text { is a Mid Volume }} C O A L_{c k t m} \leq \operatorname{maxmv} S U M_{k t m}
$$

- maximal rate for Soft coal in the mix:

$$
\sum_{c \text { is a Soft Coal }} C O A L_{c k t m} \leq \text { maxsoft } S U M_{k t m}
$$

- maximal rate for Australian coal in the mix:

$$
\sum_{c \text { is an Australian coal }} C O A L_{\text {cktm }} \leq \text { maxaus } S U M_{k t m}
$$

\section{Appendix B. Nonlinear QUAlity CONStraints On THE MIX}

Two specifications are related to the coal quantities in the mix by nonlinear relations: this two indicators are named $I 10$ and $I 20$ and have lower and upper bounds given by Table 14 .

To compute the two indicators $I 20$ and $I 10$, we need three variables:

- The first one is the mix inert rate, noted TICM, computed as the weighted sum of the inert rate of the coal in the mix.

- The second on is the agglutinating power of reactive materials in the mix, noted RCIM.

- The third one is the maximal fluidity of Gieseler of the mix, noted LGFM.

The indicator $I 20$ is computed as the following function of TICM, RCIM and $L G F M$ :

$$
\begin{aligned}
I 20= & -1.64 \times T I C M+209.1 \times R C I M+58.96 \times L G F M \\
& +.0168 \times T I C M^{2}-110.8 \times R C I M^{2}-13.16 \times L G F M^{2} \\
& -108.66 \times R C I M \times L G F M+.818 \times L G F M \times T I C M \\
& +1.015 \times L G F M^{3}+43.34 \times\left(R C I M^{2}\right) \times L G F M \\
& +6.32 \times R C I M \times L G F M^{2}-.02028 \times\left(T I C M^{2}\right) \times L G F M \\
& +.663 \times T I C M \times R C I M \times L G F M-6.1 .
\end{aligned}
$$


The indicator $I 10$ is computed as the following function of TICM, RCIM and $L G F M$ :

$$
\begin{aligned}
I 10= & 1.625 \times T I C M-200.7 \times R C I M-61.90 \times L G F M \\
& -.0159 \times T I C M^{2}+105.8 \times R C I M^{2}+12.52 \times L G F M^{2} \\
& +114.83 \times R C I M \times L G F M-.654 \times L G F M \times T I C M \\
& -.938 \times L G F M^{3}-47.02 \times\left(R C I M^{2}\right) \times L G F M \\
& -6.03 \times R C I M \times L G F M^{2}+.01761 \times\left(T I C M^{2}\right) \times L G F M \\
& -.734 \times T I C M \times R C I M \times L G F M+101 .
\end{aligned}
$$

\section{REFERENCES}

[1] A. Brooke, D. Kendrick and A. Meeraus, GAMS User's guide Release 2.25, The Scientific Press, San Francisco (1992).

[2] G. Desaulniers, J. Desrosiers and M.M. Solomon, Column Generation. Springer (2005).

[3] D. De Wolf, Using column generation to solve an industrial mixing problem, CORE Discussion Paper $\mathrm{N}^{\circ}$ 2003/42, Universit Catholique de Louvain (2003).

[4] H. Greenberg, Analyzing the pooling problem. ORSA J. Comput. 7 (1995) 205-217.

[5] L.S. Lasdon and J.C. Plummer, SLP user guide. XMP Corporation (1986).

[6] R. Sarker and E. Gunn, A simple SLP algorithm for solving a class of nonlinear programs. Eur. J. Oper. Res. 101 (1997) 140-154.

[7] F. Vanderbeck and L. Wolsey, An exact algorithm for IP column generation. Oper. Res. Lett. 19 (1996) 151-159.

[8] F. Vanderbeck, On Dantzig-Wolfe decomposition in integer programming and ways to perform branching in a branch-and-price algorithm. Oper. Res. 48 (2000) 111-128.

[9] F.J. Vasko, D.D. Newhart and A.D. Strauss, Coal blending models for optimum cokemaking and blast furnace operation. J. Oper. Res. Soc. 56 (2005) 235-243.

[10] H.P. Williams, Model building in Mathematical Programming. John Wiley (2013).

[11] H.P. Williams, Model solving in Mathematical Programming. John Wiley (1992). 